\title{
A Pós-Graduação na área de saúde do adulto e sua mobilização de recursos cognitivos
}

\author{
THE ADULT HEALTH GRADUATEAREA IN NURSING AND ITS \\ COGNITIVE RESOURCE MOBILIZATION
}

\author{
EL POS-GRADO EN LAÁREA DE SALUD DEL ADULTO Y SU MOVILIZACIÓN \\ DE LOS RECURSOS COGNITIVOS
}

\section{Cilene Aparecida Costardi Ide ${ }^{1}$, Eliane Corrêa Chaves ${ }^{2}$}

1 Enfermeira, Professora Titular (aposentada)da Escola de Enfermagem da Universidade de São Paulo (EEUSP). cilenecostardi@globo.com

2 Enfermeira, Professora Doutora do Departamento de Enfermagem MédicoCirúrgica da EEUSP. ecchaves@usp.br

\section{RESUMO}

O estudo apresenta uma análise da produção científica no período de 1994 a 2002 da área em questão, evidenciando as potencialidades do processo de desenvolvimento cognitivo de seus pesquisadores na área de Enfermagem. Identifica, ainda, os desafios que se apresentam no sentido de responder às interlocuções teóricas mais sintonizadas com a matriz geradora de distintas expressões de vida, de saúde e de doença dos adultos, foco dos investimentos de seus docentes.

\section{DESCRITORES}

Saúde do adulto.

Educação de pós-graduação em enfermagem.

Pesquisa em enfermagem.

\section{ABSTRACT}

This study analyses the scientific production of the adult health between 1994 and 2002, showing the potentialities of the process of cognitive development in researchers in the Nursing area. It also identifies the challenges for answering the theoretical dialogues between the generative matrix of different life, health and illness expressions, which is the aim of its faculty.

\section{KEY WORDS}

Adult health.

Education, nursing, graduate.

Nursing research.

\section{RESUMEN}

En este estudio se presenta un análisis de la producción científica en el período de 1994 al 2002 del área en cuestión, evidenciando las potencialidades del proceso de desarrollo cognitivo de sus investigadores en el área de Enfermería. Identifica, aún, los desafíos que se presentan en el sentido de responder a las interlocuciones teóricas que más sintonizan con la matriz generadora de distintas expresiones de vida, de salud $\mathrm{y}$ de enfermedad de los adultos, foco de inversión de sus docentes.

\section{DESCRIPTORES}

Salud del adulto.

Educación de postgrado en enfermería.

Investigación en enfermería. 


\section{INTRODUÇÃO}

A inclusão da Saúde do Adulto no âmbito da pós-graduação em Enfermagem veio se constituindo gradativamente, inclusive na Escola de Enfermagem da USP (EEUSP), ao longo das décadas de 8090, por meio do diálogo entre pressupostos teóricos, que ampliavam a concepção do ser adulto pela inclusão da perspectiva multidimensional, e os desafios de um contexto de prática mobilizado por referenciais de competência pautados numa perspectiva clínica ampliada, requerendo novos cenários e posicionamentos teórico-instrumentais.

Originária da inter-relação desses interesses, a proposta de criação da pós-graduação em Saúde do Adulto na EEUSP visava uma abordagem clínica complexa, imersa em uma malha de temas específicos, considerando eventos significativos neste âmbito de atenção à saúde. Esses temas pressupunham uma inter-relação por meio da qual diferentes demandas por cuidar seriam consideradas enquanto elementos norteadores da construção e validação de um saber-fazer-ensinar e pesquisar, numa ação qualificada, tendo por base teorias subjacentes às praticas em mobilização.

Esta construção deveria validar uma concepção de desempenho profissional que, sintonizado às mobilizações que vêm ocorrendo nos mundos da formação e do trabalho em saúde, privilegiaria a coordenação de processo de cuidar, atendendo às demandas por um profissional competente para conceber e fazer evoluir a atuação clínica, tendo por base um pensamento crítico, recorrendo à pesquisa e à prática reflexiva.

No que se refere à produção de conhecimento, a área deveria privilegiar campos temáticos aptos a sustentar uma representação de ser multidimensional, superando abordagens que vem perpetuando polaridades pouco conciliáveis. Já não se tratava de reduzir a pesquisa à reiteração de medidas prescritivas ou protocolares e nem à abordagens apresentadas em oposições às clássicas, tais como: corpo-mente; biológico-psicológico; individual-coletivo; preventivo-curativo, dentre outras representações dicotomizadas. Mas, de construir linhas de investigação abertas ao sujeito em sua dinâmica de vida e saúde-doença, considerando expressões destas experiências como núcleos processantes de investimentos clínicos peculiares, em diferentes cenários contextos e dinâmicas de prática.

Complementando esta formulação, emergia a dimensão do trabalho e das suas conseqüências e implicações, compondo uma gama de disciplinas e projetos de pesquisa que buscavam compreender e propor formas de lidar com a trama de significados, de expressões e de repercussões do trabalho na vida de profissionais e de doentes, buscando alternativas mais saudáveis, mais adaptativas e mais qualificadas de convívio.

Estas teriam sido as pedras angulares da formulação de uma Área que, no concreto, tornou-se elemento e produto de múltiplas apropriações capazes de reiterar ou gerar novos pensamentos, novas concepções e novas atitudes em relação ao cuidar e ao construir saberes sobre o cuidar.

Frente a estas considerações, cabe esboçar perspectivas para a análise de uma produção de conhecimento quantitativamente significativa, com uma expressão consistente, crescente e sustentada, mas que, sendo ciência, traz em seu bojo o espaço e o desafio dos questionamentos, cabendo-nos propor possibilidades de apreensão de aspectos dessa construção do saber. É nesta perspectiva que o presente estudo foi desenvolvido tendo por objetivo:

- Analisar a produção científica da área de concentração em Saúde do Adulto, identificando dispositivos de mobilização em seus referenciais.

\section{ABORDAGEM METODOLÓGICA}

O material analisado baseou-se nas teses de doutorado e nas dissertações de mestrado produzidas no período de 1994 a 2002, provenientes da Área de Enfermagem na Assistência à Saúde do Adulto Institucionalizado do Programa de Pós Graduação em Enfermagem da Escola de Enfermagem da Universidade de São Paulo. Cumpre esclarecer que a escolha do intervalo temporal deu-se pelo fato de corresponder ao período entre o início da área como tal e o seu término, em função de sua transformação no Programa de Enfermagem na Saúde do Adulto.

A utilização deste material para análise foi previamente consentido pelo Departamento ao qual a Área em questão estava vinculada e pelo conjunto de docentes cadastrados como seus orientadores no período analisado.

A pesquisa teve um caráter exploratório-descritivo, numa abordagem qualitativa, cujo método de análise foi a análise de conteúdo ${ }^{(1)}$.

\footnotetext{
Este método busca compreender os sujeitos analisados ou o cenário onde se encontram, por meio das partes observáveis. Contrariamente à lingüística, que apenas se ocupa das formas e da sua distribuição, a análise de conteúdo toma em consideração as significações (conteúdo), eventualmente a sua forma e a distribuição destes conteúdos e formas (índices formais e análise de co-ocorrência) ${ }^{1: 43}$.
}

A Pós-graduação na área de saúde do adulto e a sua mobilização de recursos cognitivos 
Cilene Ap. Costardi Ide Eliane Corrêa Chaves
Ela procura conhecer aquilo que está por trás das palavras sobre as quais se debruça e, para isto, trabalha com unidades lingüísticas superiores à frase (enunciados), formula as regras de encadeamento destas para descrever as unidades (as macrounidades que são os enunciados) e a sua localização numa contigüidade ${ }^{(1)}$. Neste estudo, a análise ocorreu por agrupamentos analógicos e progressivos das unidades de registro que culminaram nas categorias centrais apresentadas a seguir.

\section{A PRODUÇÃO DE CONHECIMENTO DA ÁREA: TRAÇOS DE UM PERFIL}

A análise do acervo produzido pelos pesquisadores da Área identificou a confirmação de uma identidade profissional pautada em especialidades, com uma interação ainda frágil. Assim, aspectos de um cuidar específico e de um contexto de prática também específico confirmaram espaços e atuações auto referentes e circunscritos, delineando poucos movimentos no sentido de novas configurações e de novos percursos possíveis neste campo.

Nesta perspectiva, foi-se reiterando uma representação de ser adulto fragmentada, ainda pouco sensível aos processos de co-construção pessoa-meio. A representação do ser adulto pareceu restringir-se à existência concreta de um corpo aparentemente imune aos sentimentos, relacionamentos e interações consigo, com o outro, com o ambiente.
As pesquisas no período estudado buscaram responder à questões científicas relativas a:

- A busca por expressões de construções mentais enquanto respostas a processos de adoecimentos específicos. $\mathrm{O}$ foco deste âmbito de estudo relacionou-se à identificação de percepções, sentimentos, avaliações de agrupamentos de doentes, tendo por referência a reação ao cuidado prestado;

- O rastreamento de mecanismos de respostas biológicas, com ênfase nas defesas microbiológicas mobilizadas por procedimentos invasivos;

- O acompanhamento de expressões de morbidades, no sentido de identificar respostas a investimentos terapêuticos específicos;

- A identificação de respostas individuais enquanto reação ao adoecimento, como que reduzindo a qualidade de vida a uma adaptação no sentido da sobrevivência;

- A identificação ou mensuração do impacto da ação cuidativa sobre doentes e profissionais, incluindo a vertente voltada à análise de questões iatrogênicas;

- A produções relacionadas ao ensino-aprendizagem que privilegiaram expressões de competência procedimental, tendo por foco o desempenho de técnicas especificas.

Construções ideativas relativas a conceitos e práticas experimentadas por discentes também compuseram esta vertente de interesse de pesquisa. A representação destas apreciações encontra-se caracterizada no ESQUEMA 1.

ESQUEMA 1 - Perfil identitário da construção do saber na área de concentração em saúde do adulto.

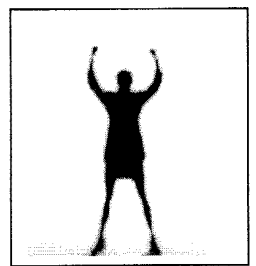

Composição do Adulto

- construções mentais apreendidas (respostas ao adoecimento);

- respostas biológicas (defesas microbiológicas);

- adoecimentos rastreados;

- vida considerada enquanto adaptação ao adoecimento

Produção

Clínica

- especificidades da prática

- categorização de eventos

- impado de ação (doente/trabalhador)

- repercussões da ação

Esses dados parecem indicar a persistência da matriz biológica na abordagem de um adulto distante de sua identidade e da sua história, quase sempre

\section{Formação}

- aprendizagem de procedimentos

- validação de estratégias

- construções ideativas acometido por uma doença específica.
Rev Esc Enferm USP 2005; 39(Esp.):564-9.

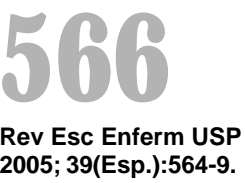

Na esfera educativa predominaram investimentos na mensuração de resultados relativos à reprodução procedimental também dissociados dos mecanismos sociológicos, didáticos e psicológicos em 
jogo no surgimento e na manutenção do desejo de saber e da decisão de aprender.

Neste sentido, foi possível identificar a persistência de uma perspectiva teórica distante do conceito de saúde-doença como um devir sensível à noção de movimento, de acontecimento em contínua mudança e reorganização, de transformação e desenvolvimento, no qual o adulto, interagindo com seu mundo, seria elemento e produto desta dinâmica. As representações desta formulação estão apresentadas no ESQUEMA 2.

ESQUEMA 2 - Núcleos temáticos hegemônicos na área de concentração em saúde do adulto.

\section{Núcleos Temáticos \\ Pesquisas \\ (Mestrado/Doutorado)}

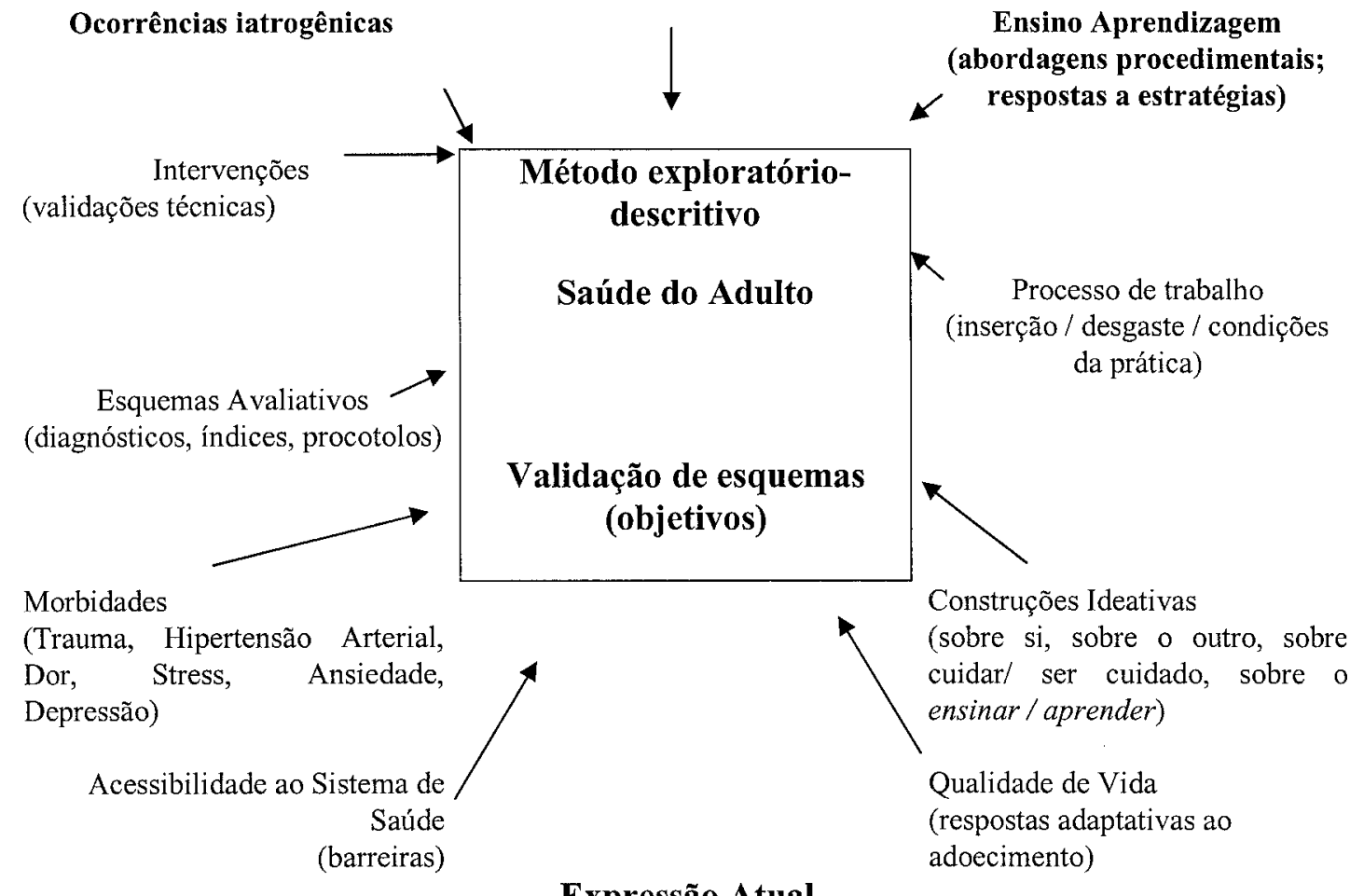

\section{Expressão Atual}

A Pós-graduação na área de saúde do adulto e a sua mobilização de recursos cognitivos
Tendo por base estes núcleos temáticos, nossa meta voltou-se à identificação do movimento intrínseco a estas produções, no sentido de apreender mobilizações dependentes da variabilidade dos significados e dos objetivos que teriam norteado a ampliação de referenciais teóricos. Esta mobilização poderia ser compreendida a partir da predisposição de pesquisadores em dialogar com referenciais teóricos ampliados, mais sensíveis à reconsideração do ser e do cuidar para além da abordagem biologizada, possibilitando novas perspectivas, tanto no delineamento das questões envolvidas nestas concepções, quanto nos procedimentos de investigação.
Apesar de reconhecermos a complexidade intrínseca aos processos de mobilizações, considerávamos possível a emergência de novas posições teóricas, advindas de processos dialéticos de fusão e de diferenciação de hábitos mentais precursores de experiências investigativas sintonizadas ao movimento das ciências.

A partir desta hipótese, reconsideramos os grupos temáticos e, efetivamente, identificamos mobilizações caracterizadas no ESQUEMA 3. 
Cilene Ap. Costardi Ide Eliane Corrêa Chaves
ESQUEMA 3 - Dispositivos de diferenciação da produção científica da área de concentração em saúde do adulto.

\begin{tabular}{cl}
\multicolumn{2}{c}{ Gradiente de evolução } \\
Concepção do adulto & $*$ corpo biológico \\
& $*$ corpo biológico e psicossocial \\
& $*$ ser humano \\
& $*$ morbidades \\
& $*$ manifestações clínicas \\
& $*$ expressões de vida - \\
Contínuo saúde-doença & saúde/doença \\
& $*$ síndrome \\
& $*$ sintoma \\
& $*$ vulnerabilidade
\end{tabular}

\author{
Projetos de Ação \\ * rastreamento \\ * proposição \\ * validação de novos projetos \\ de ação
}

Esta rede de sentidos sinalizaria uma reconsideração teórica por parte dos pesquisadores mais sensíveis a uma concepção de ciência que teria por base:

- A representação de um ser adulto mais completo e complexo,

investido da condição intransferível de construir atribuir significados e produzir investimentos singulares no seu projeto vital, promovendo formas próprias de gerar e de atender às demandas relativas à sua saúde e ao seu viver(2),

- Investimentos na personalização do atendimento na medida em que possibilita

o esclarecimento do desenrolar temporal do prognóstico, ligando-o aos movimentos relacionados (a estrutura do sujeito, sua história, seus lutos, seus investimentos afetivos, os momentos de desorganização que constituem o vetor da sua história de vida e de adoecimento) ${ }^{(3)}$;

- Uma tentativa de assimilar a possibilidade de valorizar a perspectiva desse paciente adulto relativizando a hegemonia da ótica profissional;

- Uma predisposição ainda frágil de valorização da esfera da conscientização, buscando acessar aspectos criativos do pensamento individual acerca da própria vida, da saúde e da doença;
- Uma concepção do processo saúde-doença, sinalizando a superação da explicação da doença a partir da explicitação da rede de causalidade. Haveria indícios de uma percepção de morbidade como um fenômeno também psicossocial, possibilitando o confronto entre o significado (social) da experiência e o sentido (pessoal) que lhe é dado pelo indivíduo ${ }^{(4)}$;

- A tentativa de superar abordagens, eventos de vida reduzidos à experiência em si buscando, agora, o sentido pessoal que eles teriam para o indivíduo, explorando mais as interfaces entre a representação e o comportamento, entre o pensamento e a atividade, buscando acessar o que embasa a ação ${ }^{(4)}$;

- Nessa perspectiva, a palavra de ordem não seria apenas educar mas conscientizar, tornando transparente o que era opaco e enfatizando os aspectos criativos do pensamento individual acerca da sua vida, de sua saúde e de sua doença;

- Como síntese deste realinhamento teórico haveria uma ampliação no foco das pesquisas, ainda concentradas em eventos fisiopatológicos, porém já possibilitando o surgimento do conceito de vulnerabilidade. Esta construção também decorreria de uma possibilidade de subjetivação dos eventos estudados na medida em que 
pessoas lidam e percebem seus riscos (e dos outros) de modos variados, pois eles envolvem aspectos que ultrapassam os saberes científicos e mesclam dimensões simultaneamente biológicas, psicológicas e sócio culturais ${ }^{(5)}$;

Assim sendo, consideramos que as mobilizações identificadas teriam trazido os adultos, seus processos de adoecimento e as práticas adotadas para o seu cuidado para uma base ampliada de investigação, passível de já estar agregando concepções psicossociais, evocando a natureza "construída" das respectivas expressões de saúde-doença. Dessa forma, identificamos movimentos nos constructos produzidos, já refletindo uma visão mais integrada e compreensiva dos eventos pesquisados, evoluindo de conceitos isolados para construções ideativas mais próximas das redes de significações, agregando articulações passíveis do apreender a complexidade em que as pessoas e seus processos de desenvolvimento se encontram imersas,

\begin{abstract}
disponibilizando um conjunto de significados os quais se constituem como mediadores de cursos prováveis de ação do conjunto de pessoas participantes de uma situação, ... estabelecendo possibilidades e limites à situação, aos comportamentos e ao desenvolvimento das pessoas ${ }^{(6)}$,
\end{abstract}

com ênfase no processamento de expressões de saúde-doença.

Como síntese dessa dinâmica de aprimoramento cognitivo do grupo, emerge uma produção que também tem seus objetivos potencializados na medida em que, superando investimentos no rastreamento de eventos, vêm privilegiando a validação de novos projetos de ação, ainda que, às vezes, dependentes de referências com uma sustentação teórica questionável ainda que hegemônica.
Talvez, o desvendamento parcial ou induzido das condições e razões para a replicação de "modelos” auto-aplicáveis de um pensamento clínico aprioristicamente formatado justifique a adesão identificada a movimentos que em nome de uma "identidade profissional" poderiam estar cometendo imprecisões teóricas facilmente identificáveis.

Em suma, o espaço do aprimoramento, da expansão e da discussão estão efetivamente postos no conjunto da produção científica analisada, tornando-a permeável a novos investimentos no caminho da flexibilização das certezas e das convicções, engajando o grupo na difícil tarefa de superar a si mesmo.

\section{CONSIDERAÇÕES FINAIS}

Este texto teve por finalidade explorar a produção de um grupo de pesquisadores que, com base nas avaliações da CAPES, pode ser considerado como uma das referências para Saúde do Adulto no contexto nacional. Suas contribuições ainda se vinculam aos conceitos e práticas sócio-médicas organizadas em torno do processo de adoecimento.

Entretanto, as mobilizações já se fazem presente, tendo sido possível identificar a expansão do quadro de referências, assim como a produção de resultados pautados em novas expressões de ação algumas vezes inéditas.

Efetivamente, o grupo estaria se aproximando de uma nova epistemologia, com fundamentos mais integrados e sintonizados com a interdisciplinaridade imprescindível para os pesquisadores que têm o ser humano, concebido como produto e produtor de realidades possíveis, como foco de investimentos no âmbito da Saúde do Adulto.

\section{REFERÊNCIAS}

(1) Bardin L. Análise de conteúdo. Lisboa: Edições 70; 1977.

(2) Seabra TMR. A dimensão psicossocial do cuidar na Enfermagem: a expressão representacional da práxis. [dissertação] São Paulo (SP): Escola de Enfermagem da USP; 1999.

(3) Dejours C. O corpo entre a biologia e a psicanálise. Porto Alegre: Artes Médicas; 1998.
(4) Spink MJP. A construção social do saber sobre saúde e doença: uma perspectiva psicosssocial. Saúde e Soc 1992; 1(2):125-39.

(5) Castill LDA. A medida do possível: saúde, risco e tecnobiociências. Rio de Janeiro: Fiocruz; 1999.

(6) Rossetti FMC, Amorim KS, Silva APS, Carvalho AMA, organizadores. Rede de significações e o estudo do desenvolvimento humano. Porto Alegre: Artes Médicas; 2004.
A Pós-graduação na área de saúde do adulto e a sua mobilização de recursos cognitivos
Correspondência: Cilene Ap. Costari Ide Av. Dr. Enéas de C. Aguiar, 419 - Cerqueira César - São Paulo 05403-000 - SP 